DE

M E D I C I N A

T R O P I C A L

$\mathrm{DE}$

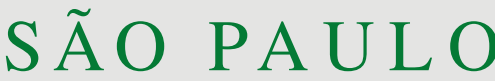

JOURNAL OF THE SÃO PAULO INSTITUTE OF TROPICAL MEDICINE

${ }^{1}$ Universidade Federal de Mato Grosso, Hospital Universitário Julio Muller, Laboratório de Análises Clínicas, Divisão de Microbiologia, Cuiabá, Mato Grosso, Brazil

${ }^{2}$ Universidade de São Paulo, Instituto de Medicina Tropical de São Paulo, Laboratório de Soroepidemiologia e Imunobiologia, São Paulo, São Paulo, Brazil

3Universidade de São Paulo, Faculdade de Medicina, Departamento de Moléstias Infecciosas e Parasitárias, LIM 48, São Paulo, São Paulo, Brazil

${ }^{4}$ Universidade Federal do Mato Grosso, Faculdade de Medicina, Departamento de Pediatria, Cuiabá, Mato Grosso, Brazil

5Universidade de São Paulo, Faculdade de Medicina, Departamento de Pediatria, São Paulo, São Paulo, Brazil

'Universidade de São Paulo, Faculdade de Medicina, Hospital das Clínicas, Instituto da Criança, Laboratório de Pediatria Clínica, LIM 36, São Paulo, São Paulo, Brazil

Correspondence to: Kelly Aparecida Kanunfre

Universidade de São Paulo, Instituto de Medicina Tropical de São Paulo, Laboratório de Soroepidemiologia e Imunobiologia, Avenida Doutor Enéas de Carvalho Aguiar, 470, Prédio II, $4^{\circ}$ andar, Cerqueira Cesar, CEP 05403-000, São Paulo, SP, Brazil Tel: +55 11 3061-7022,

Fax: +55 11 3061-8270

E-mail: kanunfre@usp.br

Received: 12 April 2018

Accepted: 2 October 2018

\section{Assessment and comparison of bacterial load levels determined by quantitative amplifications in blood culture-positive and negative neonatal sepsis}

\author{
Inês Stranieri', Kelly Aparecida Kanunfre ${ }^{2,3}$, Jonatas Cristian Rodrigues ${ }^{2,3}$, \\ Lidia Yamamoto ${ }^{2}$, Maria Isabel Valdomir Nadaf ${ }^{4}$, Patricia Palmeira ${ }^{5,6}$, Thelma \\ Suely Okay ${ }^{2}$
}

\section{ABSTRACT}

Bacterial sepsis remains a major cause of mortality and blood cultures are the gold standard of laboratory diagnosis even though they lack sensitivity in neonates. Culturenegative sepsis, also known as clinical sepsis, has long been considered a diagnosis in neonatal intensive care units because, as well as culture-positive infants, culture-negative neonates have worse prognosis in comparison with non-infected ones. Quantitative amplifications are used to detect bacterial infections in neonates but results are considered only in a qualitative way (positive or negative). The aim of the present study was to determine and compare bacterial load levels in blood culture-positive and culture-negative neonatal sepsis. Seventy neonates with clinical and laboratory evidence of infection admitted at three neonatal intensive care units were classified as blood culture-positive or culture-negative. Blood samples obtained at the same time of blood cultures had bacterial load levels assessed through a $16 \mathrm{~S}$ rDNA qPCR. Blood cultures were positive in 29 cases (41.4\%) and qPCR in 64 (91.4\%). In the 29 culture-positive cases, $100 \%$ were also positive by qPCR, while in the 41 culture-negative cases, $35(85.4 \%)$ were positive by qPCR. Bacterial load levels were in general $<50 \mathrm{CFU} / \mathrm{mL}$, but were significantly higher in culture-positive cases (Mann-Whitney, $\mathrm{p}=0.013$ ), although clinical and laboratory findings were similar, excepting for deaths. In conclusion, the present study has shown that blood culture-negative neonates have lower bacteria load levels in their bloodstream when compared to blood culture-positive infants.

KEYWORDS: Blood culture. Culture-negative neonatal sepsis. Neonatal blood stream infection. Real Time PCR. 16S rDNA.

\section{INTRODUCTION}

Worldwide, infections cause $40 \%$ of the estimated 1.6 million neonatal deaths each year ${ }^{1,2}$. Blood cultures are the gold standard of diagnosis but positivity is particularly low in neonates ${ }^{3}$. Factors such as only one blood culture performed per infection episode, blood collection performed in only one site, delayed entry of culture bottles into machines and mainly the low blood volumes inserted into culture bottles ${ }^{4-6}$ are associated with this low positivity ${ }^{7-9}$.

Given the potentially severe sequelae of neonatal infections, the myriad of presentations of neonatal sepsis and the limitations of blood culture sensitivity, culture-negative sepsis (clinical sepsis), has long been accepted as a diagnosis in neonatal intensive care units. This diagnosis has persisted due to the presumption that neonatologists are able to recognize infected neonates even though signs/symptoms 
are not specific. In addition, several reports have shown that neonates with blood culture-positive or culture-negative sepsis will present higher rates of neurodevelopmental impairment compared to non-infected infants, emphasizing the need to better characterize these blood culture-negative cases $^{10}$.

Opposing these ideas, in a recent report, the authors have criticized the skepticism to trust blood culture results, especially when they are negative in suspected cases of neonatal sepsis. They questioned the unintended harm caused by prolonged or unnecessary use of antibiotics which expose infants to an increased risk of obesity, atopy and, for preterm infants, to necrotizing enterocolitis, bronchopulmonary dysplasia, sepsis and death. However, these authors have made it clear that reliability of blood culture results depends on the application of correct blood collection techniques, the use of appropriate culture bottles, the rapid referral of samples to the laboratory and in particular, the use of adequate blood volumes ${ }^{11}$.

In recent years, quantitative Polymerase Chain Reaction amplification (qPCR) has proved to be more sensitive than blood culture and conventional PCR, determining the load of microorganisms and releasing faster results. The time required for the final release of positive cultures varies from 24 to $72 \mathrm{~h}$, while the release of negative results takes much longer, approximately five days. This is the main factor that makes neonates with an initial suspicion of infection to receive antibiotics for at least five days, increasing the risks of infections associated with health care. This extended amount of time of blood culture results contrasts with that of qPCR, which can release positive or negative results within $24 \mathrm{~h}^{12-14}$.

The aim of the present study was to assess and compare bacterial load levels determined by qPCR in culture-positive and culture-negative cases of neonatal sepsis. Bacterial load levels were analyzed with respect to clinical and laboratory findings.

\section{MATERIAL AND METHODS}

\section{Neonates and their mothers}

This research was approved by the Research Ethics Committee of the participating institutions (CAPPesq process $\mathrm{N}^{\circ} 0889 / 09$ and 587/CEP-HUJM/08). Neonates were from three neonatal intensive care units (NICUs) of public tertiary care hospitals: Federal University of Mato Grosso, Cuiaba, Mato Grosso (10 beds); Santa Helena Hospital, Cuiaba, Mato Grosso (20 beds) and the Children's Institute, University of Sao Paulo, Sao Paulo (20 beds).

This is a prospective cohort study of neonates with symptomatology and laboratory exams indicative of sepsis, randomized according to blood cultures results (positive or negative).

\section{Mothers}

Regarding the mothers, demographic data such as age, prenatal care, parity, type of delivery, diseases during pregnancy and use of antibiotics were retrieved from medical records.

\section{Inclusion criteria of neonates}

Neonates had to present at least two signs/symptoms suggestive of infection ${ }^{15}$ associated with at least two abnormal laboratory parameters in the complete blood count and C-Reactive Protein (CRP) analyses. The reference values to consider the parameters abnormal were leukocytosis $\left(>20,000 / \mathrm{mm}^{3}\right)$, leukopenia $\left(<5,000 / \mathrm{mm}^{3}\right)$, neutrophilia $\left(>13,000 / \mathrm{mm}^{3}\right)$, neutropenia $\left(<1,000 / \mathrm{mm}^{3}\right)$, neutrophil index $>0.2$ (immature neutrophil count/total), thrombocytopenia $\left(<100,000 / \mathrm{mm}^{3}\right)$, and CRP $>10 \mathrm{mg} / \mathrm{mL}^{16,17}$.

\section{Exclusion criteria of neonates}

Exclusion criteria were surgical procedures, presence of severe perinatal asphyxia defined by an Apgar score of less than 4 at $5 \mathrm{~min}$ of life ${ }^{18}$, presence of congenital malformation or congenital infections.

\section{Blood sampling and blood culture}

Blood sampling was performed at the time of admission to the neonatal intense care unit (NICU) before the initiation of antibiotics. The recommendation adopted in the study was the collection of two millilitres $(\mathrm{mL})$ of blood from peripheral venepuncture $(1 \mathrm{~mL}$ for blood culture and $1 \mathrm{~mL}$ for qPCR), after a careful and exhaustive forearm cleaning with $2 \%$ alcoholic chlorhexidine digluconate in $70 \%$ ethanol to avoid contamination with bacteria that colonize the skin such as coagulase-negative Staphylococcus.

The culture of aerobic and anaerobic organisms was performed in the BACT ALERT 3D, BioMerieux ${ }^{\circledR}$.

\section{Blood samples from non-infected neonates}

Due to a recommendation of the Research and Ethics Committees from the participating institutions, the collection of blood samples from neonates without infection was not allowed. Therefore, two millilitres of blood (one millilitre for blood culture and one millilitre for quantitative PCR), were collected directly from placenta (cord blood) of 
10 full term neonates whose mothers attended the prenatal care and did not present any evidence of infection. Blood collection was performed at the delivery room, by trained nurses, using a sterile specialized kit. The disinfection procedure was performed by a single cleaning step with $70 \%$ ethanol. These samples were used as negative controls in the qPCR experiments after checking that the corresponding blood cultures were negative.

\section{DNA extraction}

From this stage, all the manipulations were performed under sterile conditions. The disposable items were autoclaved, and the reagents were filtered through $0.22 \mu \mathrm{m}$ filters (Merck-Millipore, Billerica, MA, USA). Blood samples were submitted to DNA extraction using the QIAamp DNA mini kit (QIAGEN Inc., Hilden, Germany) with the addition of a specific step to optimize bacterial DNA extraction ${ }^{19,20}$.

\section{Quantitative PCR (qPCR)}

The qPCR used in this study has been previously described $^{21}$. Briefly, amplifications were performed in an ABI StepOne Real Time PCR System (Applied Biosystems ${ }^{\circledR}$, Foster City, CA, USA). The reagents mixture had a final volume of $25 \mu \mathrm{L}$ and contained QuantiFast SYBR Green PCR Master Mix (QIAGEN Inc., Hilden, Germany), $0.1 \mu \mathrm{M}$ of the forward and reverse primers (forward 5' - CAGCTCGTGTCGTGAGATGT-3' and reverse 5'- CGTAA GGGCCATGATGACT- 3') and $100 \mathrm{ng}$ of genomic DNA from the neonates with suspected sepsis. Negative controls contained $100 \mathrm{ng}$ of genomic DNA from non-infected infants. An additional negative control containing sterile water (non-template sample) was added to each experiment. Positive samples generated a $150 \mathrm{bp}$ amplification product. All samples were tested in triplicate. Forty cycles of amplification were performed: $95{ }^{\circ} \mathrm{C}$ for 5 min followed by 10 cycles of $95{ }^{\circ} \mathrm{C}$ for $30 \mathrm{~s}$ and $66^{\circ} \mathrm{C}$ for $30 \mathrm{~s}, 10$ cycles of $95{ }^{\circ} \mathrm{C}$ for $30 \mathrm{~s}$. and $64^{\circ} \mathrm{C}$ for $30 \mathrm{~s}$, and 20 cycles of $95^{\circ} \mathrm{C}$ for $30 \mathrm{~s}$ and $62^{\circ} \mathrm{C}$ for $30 \mathrm{~s}$, ending with the melting curve.

The standard qPCR curve was built using cultures of Gram-positive (Staphylococcus aureus ATCC 25923 and Staphylococcus epidermidis ATCC 12228) and Gram-negative bacteria (Pseudomonas aeruginosa ATCC 27853, Escherichia coli ATCC 25922 and Klebsiella pneumoniae ATCC 700603). The concentration of bacteria equivalent to 0.5 in the McFarland turbidity scale was assumed to correspond to $10^{8} \mathrm{CFU} / \mathrm{mL}$ (CFU = Colony Forming Units) according to Zucol et al. $.^{20} \mathrm{Then}, 10^{8} \mathrm{CFU}$ in
$1.0 \mathrm{~mL}$ of saline solution or $10^{8} \mathrm{CFU} / \mathrm{mL}^{22}$ was centrifuged at $20,817 \mathrm{x}$ g for $10 \mathrm{~min}$ at $4{ }^{\circ} \mathrm{C}$, and the pellet was placed in $0.2 \mathrm{~mL}$ of whole blood collected in EDTA tubes from a known uninfected individual. Subsequently, these $0.2 \mathrm{~mL}$ of blood containing $10^{8}$ bacteria had DNA extracted with a commercial kit. At the end of the DNA extraction, the resulting DNA was eluted in $1 \mathrm{~mL}$ of Tris-EDTA buffer. This final DNA sample contained $10^{8}$ bacteria per $\mathrm{mL}$. Then, the calibration curve of qPCR was constructed beginning with 10 microliters of this DNA solution that corresponds to $10^{6}$ bacteria, and serial $1 / 10$ dilutions were made from $10^{6}$ bacteria up to $1 \mathrm{CFU}$. The limit of detection was $1-10^{1}$ $\mathrm{CFU} / \mathrm{mL}$ (the concentration in which $95 \%$ of samples are positive, i.e. 19 tests out of 20$)^{23}$, regardless of the type of bacteria, Gram-positive or Gram-negative ${ }^{21}$.

\section{Statistical Analysis}

To determine the minimum sample size of the study, we assumed that blood cultures would have a sensitivity of 50\%, a rather optimistic percentage, and the qPCR a sensitivity of $99 \%$. As the primary outcome of the study is the difference between positivity of blood culture and qPCR, patients were randomized according to blood culture results (blood culture-positive and blood culture-negative subgroups). We also assumed and alpha error of 5\% $(\mathrm{p}<0.05)$ and a beta error of $80 \%(0.8)$ and used the applicative statstodo.com, section of sample size calculation, that resulted in a minimum of 13 samples in each subgroup ( $\mathrm{ss} \mathrm{U}=$ sample size per group for unpaired comparisons). Consequently, the minimum sample size of the study would be 26 cases ( 13 culture-positive and 13 culture-negative neonates).

Comparisons of the median values of the bacterial load levels between blood culture-positive and blood culturenegative groups were performed using the Mann-Whitney Wilcoxon test, considering significant p-values $<0.05$, in a confidence interval of $95 \%$. The Fisher's exact test was used for comparisons of proportions and frequencies when $\mathrm{n}<5$ and in these cases, no confidence interval could be established. The statistical program used was the GraphPad Prism, version 6.0 (GraphPad Prism Software Inc., CA, USA). Values of $\mathrm{p}<0.05$ were considered significant, with a confidence interval of $95 \%$.

\section{RESULTS}

\section{Clinical and laboratory data}

Regarding the 70 mothers, data on maternal age, type of delivery, number of previous deliveries, if they received 
prenatal care or not, maternal diagnosis during pregnancy and use of antibiotics during pregnancy are in Table 1. The maternal parameters were compared according to neonatal blood culture results, positive or negative, statistical significant difference was found only in the number of maternal diagnosis (urinary tract infection, premature rupture of membranes, placental abruption and hypertensive disorder of pregnancy), more frequent in the culture negative group $(\mathrm{p}<0.001)$.

There were 18 preterm and 11 full-term infants $(n=29)$ in the group of culture-positive neonates, and 31 preterm and 10 full-term neonates $(n=41)$ in the culture-negative group (Table 1). Considering the neonatal parameters (gestational age, birth weight, deaths), the only statistical significant difference was found with respect to deaths ( $p<0.001)$, as the total 8 deaths occurred in the culture-positive group, in 7 preterm and 1 full-term infant (Table 1).

All neonates, irrespective of the group (culture-positive or culture-negative) received antibiotics, varying from ampicillin and gentamicin (first choice) to vancomycin,

Table 1 - Maternal and neonatal data in culture-positive and culture-negative groups.

\begin{tabular}{|c|c|c|c|c|c|c|c|}
\hline & \multirow{3}{*}{ Variables } & & \multicolumn{4}{|c|}{ Blood culture } & \multirow{3}{*}{$p$-value ${ }^{\S}$} \\
\hline & & & \multicolumn{2}{|c|}{ Positive $(\mathrm{N}=29)$} & \multicolumn{2}{|c|}{ Negative $(\mathrm{N}=41)$} & \\
\hline & & & $\begin{array}{c}\text { Preterm } \\
\mathrm{N}=18\end{array}$ & $\begin{array}{c}\begin{array}{c}\text { Full-term } \\
\mathrm{N}=11\end{array} \\
\end{array}$ & $\begin{array}{c}\text { Preterm } \\
\mathrm{N}=31\end{array}$ & $\begin{array}{c}\begin{array}{c}\text { Full-term } \\
\mathrm{N}=10\end{array} \\
\text {. }\end{array}$ & \\
\hline \multicolumn{3}{|l|}{ Maternal age $\left(\right.$ years) ${ }^{\star}$} & 19 & 23 & 25 & 20 & $p=0.12$ \\
\hline \multirow{3}{*}{\multicolumn{2}{|c|}{ Type of delivery }} & Vaginal & 8 & 5 & 11 & 7 & \multirow{3}{*}{$\begin{array}{c}p=0.61 \\
\text { Cl: }-0.15 \text { to } 0.31\end{array}$} \\
\hline & & Cesarean & 9 & 3 & 20 & 3 & \\
\hline & & $\mathrm{N} / \mathrm{A}$ & 1 & 3 & 0 & 0 & \\
\hline \multirow{3}{*}{\multicolumn{2}{|c|}{ No. of previous deliveries }} & 1 & 4 & 4 & 4 & 1 & \multirow{3}{*}{$p=0.08$} \\
\hline & & $\geq 2$ & 6 & - & 10 & 5 & \\
\hline & & $\mathrm{N} / \mathrm{A}$ & 8 & 7 & 17 & 4 & \\
\hline \multirow{3}{*}{\multicolumn{2}{|c|}{ Prenatal care }} & Yes & 7 & 3 & 11 & 5 & \multirow{3}{*}{$p=1.00$} \\
\hline & & No & 1 & - & 1 & 1 & \\
\hline & & $\mathrm{N} / \mathrm{A}$ & 10 & 8 & 19 & 4 & \\
\hline \multirow{3}{*}{\multicolumn{2}{|c|}{ Maternal diagnosis in pregnancy }} & Yes & 12 & 4 & 19 & 7 & \multirow{3}{*}{$p<0.001$} \\
\hline & & No & 5 & 4 & 0 & 0 & \\
\hline & & $\mathrm{N} / \mathrm{A}$ & 1 & 3 & 12 & 3 & \\
\hline \multirow{2}{*}{\multicolumn{2}{|c|}{ Maternal antibiotics in pregnancy }} & Yes & 4 & 2 & 5 & 1 & \multirow{2}{*}{$p=0.53$} \\
\hline & & N/A & 14 & 9 & 26 & 9 & \\
\hline \multicolumn{3}{|c|}{ Gestational age (weeks) ${ }^{*}$} & 32 & 38,5 & 34 & 38 & $p=0.66$ \\
\hline \multicolumn{3}{|l|}{ Birth weight (grams)* } & 1,795 & 2,937 & 2,035 & 3,104 & $p=0.36$ \\
\hline \multicolumn{3}{|l|}{ Death } & 7 & 1 & 0 & 0 & $p<0.001$ \\
\hline \multicolumn{3}{|c|}{ AMP+Cpe } & 6 & 2 & 1 & - & $\mathrm{NC}$ \\
\hline \multicolumn{3}{|c|}{$\mathrm{AMP}+\mathrm{GEN}$} & 9 & 5 & 28 & 9 & NC \\
\hline \multicolumn{3}{|c|}{$\mathrm{AMP}+\mathrm{Cpe}+\mathrm{MEM}+\mathrm{GEN}$} & 1 & - & - & - & NC \\
\hline \multirow[t]{4}{*}{ Neonatal antibiotics } & \multicolumn{2}{|c|}{$\mathrm{AMP}+\mathrm{GEN}+\mathrm{Cpe}$} & 1 & 1 & 1 & - & NC \\
\hline & \multicolumn{2}{|c|}{$\mathrm{AMP}+\mathrm{Cpe}+\mathrm{Van}+\mathrm{MEM}$} & - & - & 1 & - & NC \\
\hline & \multicolumn{2}{|c|}{$\mathrm{AMP}+\mathrm{GEN}+\mathrm{CFL}$} & - & - & - & 1 & NC \\
\hline & \multicolumn{2}{|c|}{ Cpe+Van+MEM } & 1 & 3 & - & - & NC \\
\hline
\end{tabular}

Comparisons were made between culture-positive and culture negative neonates. $₫ p$-value was calculated by the Fisher's exact test when cell counts were < 5, or by Mann-Whitney Wilcoxon. The confidence interval, $\mathrm{Cl}$ of $95 \%$ was established whenever possible, ${ }^{*}$ median values were considered to analyze maternal age, gestational age and birth weight of neonates at birth; other analyzes considered the number of cases in each category and then comparisons were made between culture-positive and negative groups. N/A: not available; No: number; " maternal diagnosis: urinary tract infection, premature rupture of membranes, placental abruption and hypertensive disorder of pregnancy; NC- not calculated; AMP: Ampicillin; GEN: Gentamicin; Cpe: Cefepime; MEM: Meropenem; VAN: Vancomycin; CFL: cephalexin. 
cefepime and meropenem, for periods of 1 to 3 weeks (Table 1).

On admission to the NICU, the median age of infants was 9 days old (minimum 02 - maximum 15) in either culture-positive or negative neonates.

Among the 29 blood culture-positive cases, there were 26 Gram-positive bacteria: 19 coagulase-negative Staphylococcus, 2 Staphylococcus aureus, 2 Streptococcus agalactiae, 1 Streptococcus pneumoniae, 1 Streptococcus viridans and 1 Lysteria monocytogenes. In addition, three Gram-negative bacteria were found: 2 Klebsiella pneumoniae and 1 Pseudomonas aeruginosa.

The most frequent clinical manifestations were respiratory distress and mild to moderate perinatal asphyxia, while the most common laboratory abnormalities were leukopenia, neutrophilia, thrombocytopenia, and $\mathrm{CRP}>10 \mathrm{mg} / \mathrm{L}$. It was noteworthy that the culture-positive and -negative groups had similar frequencies of clinical and laboratory abnormalities (Table 2).

Among the 29 blood culture-positive neonates, 29 presented positive qPCR (100\%). Considering the 41 culture-negative cases, $35(85.4 \%)$ presented positive and six $(14.6 \%)$ had negative qPCR. Clinical and laboratory data of the six cases with negative blood culture and qPCR results are in Table 3.

The comparison between the median of bacterial load levels in the group of blood culture-positive infants (40.84 CFU/mL; minimum 6.6 - maximum 120.90) and blood culture-negative ones $(25.13 \mathrm{CFU} / \mathrm{mL}$; minimum 1.28 - maximum 41,419) found a statistically significant difference (Mann-Whitney, $\mathrm{p}=0.013$; Figure 1). Nevertheless, qPCR did not find higher bacterial load levels in these 8 neonates who died when they were compared with the other 21 infants belonging to the culture-positive group (Mann-Whitney Wilcoxon, $\mathrm{p}=0.59)$.

Culture-positive and culture-negative groups were arbitrarily divided into five subgroups according to their bacterial load levels (Table 4). Only in the range of $50-10^{2}$ bacteria/CFU there were significantly more cases in the culture-positive group ( $\mathrm{p}=0.034$ ).

Regarding the culture-positive group, the full-term infant in whom a Streptococcus agalactiae was isolated, had the highest bacterial load (120.9 CFU/mL). This infant received ampicillin, gentamycin and cefepime for two weeks and evolved favourably.

In the culture-negative group, there were two preterm infants with bacterial load levels above $10^{2} \mathrm{CFU} / \mathrm{mL}$. The mother of the first infant had sepsis and received broad-spectrum antibiotics, with a favourable outcome. Unfortunately, no information could be retrieved on the isolation of bacteria from her blood cultures. The bacterial load of this neonate was $41,419 \mathrm{CFU} / \mathrm{mL}$. In the second case, no maternal morbidity was reported and the bacterial load of the infant was $452 \mathrm{CFU} / \mathrm{mL}$. These two neonates responded favourably after treatment with ampicillin and gentamicin (first choice of antibiotics) for two weeks.

\section{DISCUSSION}

As far as we know, this is the first study in which bacterial load levels were assessed through qPCR and were compared between a group of blood culture-positive neonates and a group of blood culture-negative ones. A

Table 2 - Clinical and laboratory parameters of the 29 blood culture-positive and the 41 blood culture-negative neonates.

\begin{tabular}{|c|c|c|c|}
\hline Clinical and laboratory parameters & $\begin{array}{c}\text { Culture-positive } \\
\mathrm{N}=29(\%)\end{array}$ & $\begin{array}{c}\text { Culture-negative } \\
\mathrm{N}=41(\%)\end{array}$ & $\begin{array}{c}p \text {-value } \\
p<0.05(95 \% \mathrm{Cl})\end{array}$ \\
\hline Respiratory distress ${ }^{*}$ & $29(100)$ & $36(88)$ & 0.730 \\
\hline Perinatal asphyxia ${ }^{\S}$ & $21(72)$ & $27(65)$ & $\begin{array}{c}0.618 \\
(\mathrm{Cl}-0.163 \text { to } 0.314)\end{array}$ \\
\hline Leukopenia & $17(58)$ & $16(39)$ & $\begin{array}{c}0.805 \\
(\mathrm{Cl}-0.176 \text { to } 0.292)\end{array}$ \\
\hline Neutrophilia & $19(65)$ & $22(54)$ & $\begin{array}{c}1.000 \\
(\mathrm{Cl}-0.212 \text { to } 0.250)\end{array}$ \\
\hline Thrombocytopenia & $16(64)$ & $24(58)$ & $\begin{array}{c}0.225 \\
(\mathrm{Cl}-0.006 \text { to } 0.397)\end{array}$ \\
\hline CRP (> 10 mg/L) & $18(62)$ & $20(49)$ & $\begin{array}{c}1.000 \\
(\mathrm{Cl}-0.226 \text { to } 0.235)\end{array}$ \\
\hline
\end{tabular}

*The respiratory distress syndrome considered fast breathing, chest wall retractions, expiratory grunting, nasal flaring, cyanosis, lethargy, irregular breathing and apnea. ${ }^{\S}$ Perinatal asphyxia considered cyanosis, perfusion abnormalities, unresponsiveness, decreased muscle tone (hypotonia) and increased respiratory effort. All signs and symptoms should have been transient, not characterizing severe asphyxia. CRP (C reactive protein). " $p$-value was calculated using the Fisher's exact test. Confidence interval of $95 \%$ was established whenever possible. 
Table 3 - Clinical and laboratory data of the six cases of neonatal sepsis included in the study that showed negative results by blood culture and qPCR.

\begin{tabular}{|c|c|c|c|c|c|c|c|c|c|}
\hline Case & Delivery & $\begin{array}{c}\mathrm{GA} \\
\text { (weeks) }\end{array}$ & $\begin{array}{l}\text { BW } \\
(\mathrm{g})\end{array}$ & $\begin{array}{l}\text { Apgar } \\
\text { score }\end{array}$ & $\begin{array}{l}\text { Maternal } \\
\text { illness }\end{array}$ & $\begin{array}{l}\text { Maternal } \\
\text { antibiotics }\end{array}$ & $\begin{array}{l}\text { PROM } \\
\text { (hours) }\end{array}$ & $\begin{array}{c}\text { Neonatal } \\
\text { diagnoses }\end{array}$ & $\begin{array}{c}\text { Laboratory } \\
\text { abnormalities }\end{array}$ \\
\hline $6 \mathrm{~T}$ & Vaginal & 39 & 2,265 & $0 / 8$ & UTI & AMP & 12 & $\begin{array}{c}\text { Respiratory } \\
\text { distress; Perinatal } \\
\text { asphyxia }\end{array}$ & $\begin{array}{c}\text { Neutrophilia, } \\
\text { Leukopenia, } \\
\text { Thrombocytopenia }\end{array}$ \\
\hline $63 \mathrm{~T}$ & $\begin{array}{l}\text { Cesarean } \\
\text { section }\end{array}$ & 39 & 3,460 & $6 / 8$ & CPD & NO & NO & $\begin{array}{c}\text { Respiratory } \\
\text { distress; Perinatal } \\
\text { asphyxia; MAS }\end{array}$ & $\begin{array}{l}\text { Neutrophilia, } \\
\text { Thrombocytopenia; } \\
\text { Increased CRP }\end{array}$ \\
\hline 47PT & $\begin{array}{l}\text { Cesarean } \\
\text { section }\end{array}$ & 36 & 2,470 & $8 / 9$ & NO & NO & NO & $\begin{array}{c}\text { Prematurity, } \\
\text { Severe lethargy; }\end{array}$ & $\begin{array}{c}\text { Neutrophilia, } \\
\text { Thrombocytopenia }\end{array}$ \\
\hline 51PT & $\begin{array}{l}\text { Cesarean } \\
\text { section }\end{array}$ & 35 & 1,865 & $5 / 8$ & NO & NO & NO & $\begin{array}{c}\text { Prematurity, } \\
\text { Respiratory } \\
\text { distress; Perinatal } \\
\text { asphyxia }\end{array}$ & $\begin{array}{l}\text { Leukocytosis, } \\
\text { Neutrophilia; } \\
\text { Increased CRP }\end{array}$ \\
\hline 60PT & Vaginal & 36 & 2,066 & $6 / 8$ & NO & AMP & 4 & $\begin{array}{c}\text { Prematurity, } \\
\text { Respiratory } \\
\text { distress; Perinatal } \\
\text { asphyxia }\end{array}$ & $\begin{array}{l}\text { Leukopenia, } \\
\text { Thrombocytopenia; } \\
\text { Increased CRP }\end{array}$ \\
\hline 67PT & $\begin{array}{l}\text { Cesarean } \\
\text { section }\end{array}$ & 34 & 1465 & $8 / 9$ & NO & NO & NO & $\begin{array}{l}\text { Prematurity, } \\
\text { Respiratory } \\
\text { distress; }\end{array}$ & $\begin{array}{l}\text { Neutrophilia, } \\
\text { Thrombocytopenia; } \\
\text { Increased CRP }\end{array}$ \\
\hline
\end{tabular}

T: full-term (37-42 weeks of gestation); PT: preterm infant (<37 weeks of gestation); GA: Gestational age; BW: Birth Weight; Apgar score was recorded in the $1^{\text {st }} / 5^{\text {th }}$ minute of life; PROM - Premature rupture of membranes; UTI - Urinary tract infection; CPD Cephalopelvic disproportion; AMP: Ampicillin; MAS - Meconium aspiration syndrome; Increased CRP (C reactive protein) > 10 mg/L.

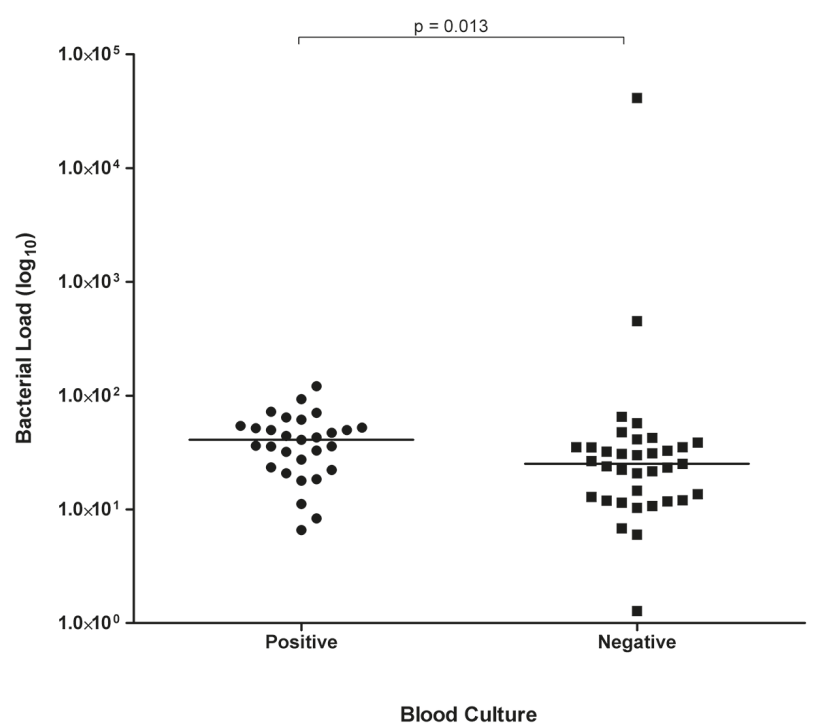

Figure 1 - Comparison of the bacterial load (CFU/mL) assessed by qPCR between the culture-positive $(n=29)$ and negative groups $(n=35)$. Mann-Whitney test, $p=0.013$. The bars represent the median values. CFU - Colony forming units; $\mathrm{mL}$ - millilitre; qPCR - quantitative Real Time PCR.

better laboratory characterization of blood culture-negative infants with sepsis is relevant because neonates with culture-negative sepsis present higher neurodevelopmental impairment rates when compared to non-infected infants ${ }^{10}$, receive antibiotics, therefore increasing hospital costs, and they remain hospitalized for prolonged periods, raising the risks of infections associated with health care.

Regarding maternal and neonatal characteristics, the only difference found between culture-positive and the culture-negative groups was the number of maternal diagnosis during pregnancy (Table 1) higher in the culturenegative group. However, given that the information on maternal treatment is lacking in the majority of cases, in both groups, this difference may not reflect the reality.

In respect to the neonates (Table 1), the gestational age, birth weight and number of deaths in the culture-positive and negative groups, the only significant difference was found in the number of deaths, as the total of 8 deaths of the study occurred in the culture positive group (7 preterm and 1 full-term infant). Albeit this difference, considering clinical and laboratory abnormalities such as respiratory distress, perinatal asphyxia, leukopenia, neutrophilia, thrombocytopenia and increased CRP, (Table 2) culturepositive and culture-negative neonates did not differ, reinforcing that only neonates with suspicion of sepsis were included in both groups.

In this study, the percentage of positive blood cultures was $41.4 \%$, a relatively high percentage in comparison with lower rates reported in other neonatal studies ${ }^{12,13,24-29}$. However, the 70 recruited cases had consistent clinical and laboratory evidence of infection (Table 2) and the 
Table 4 - Bacterial load levels determined by qPCR arbitrarily divided into five groups according to load levels, in blood culturepositive and culture-negative cases.

\begin{tabular}{|c|c|c|c|}
\hline \multirow{3}{*}{$\begin{array}{c}\text { qPCR } \\
\text { Bacterial load (CFU/mL) }\end{array}$} & \multicolumn{2}{|c|}{ Culture } & \multirow{3}{*}{$p$-value ${ }^{\#}$} \\
\hline & Positive & Negative & \\
\hline & No. of cases (\%) & No. of cases (\%) & \\
\hline 1 to 10 & $2(6.9)$ & $3(8.6)$ & $p=0.441$ \\
\hline 11 to 30 & $7(24.1)$ & $17(48.6)$ & $\begin{array}{c}p=0.115 \\
(\mathrm{Cl} 95 \%-0.022 \text { to } 0.486)\end{array}$ \\
\hline 31 to 50 & $11(38.0)$ & $11(31.4)$ & $\begin{array}{c}p=0.593 \\
(\mathrm{Cl} 95 \%-0.154 \text { to } 0.365)\end{array}$ \\
\hline 51 to $10^{2}$ & $8(27.6)$ & $2(5.7)$ & $p=0.034$ \\
\hline$>10^{2}$ & $1(3.4)$ & $2(5.7)$ & $p=1.000$ \\
\hline Total & 29 & 35 & - \\
\hline
\end{tabular}

qPCR - quantitative Real Time PCR; CFU - Colony forming units; $\mathrm{mL}$ - millilitre; No - Number; \# $p$-value was calculated using the Fisher's exact test and the confidence interval of $95 \%$ was calculated whenever possible.

participant neonatal intensive care units are reference centers in their communities, probably concentrating the most severe cases.

Regarding the etiological agents, blood cultures indicated a predominance of coagulase-negative Staphylococcus among culture-positive neonates (19/29) that were also the most frequent in the group of eight infants who evolved to death $(5 / 8)$ corroborating that this bacterium was the leading cause of infections in this study, as well as in other countries $^{30-34}$. It was also noteworthy that neonatal infections took place after the first days of life with a median age of infants on admission to the NICUs of nine days in both groups, characterizing late-onset infections. In this sense, the predominance of coagulase-negative Staphylococcus in blood cultures is in agreement with the type of infection.

Coagulase-negative Staphylococcus was detected in blood cultures of 19/29 culture-positive neonates and blood sampling was performed on admission at the NICUs. According to the medical records, a second blood culture was not performed to confirm whether infections were true or due to skin contamination, probably because these neonates were critically ill at least during the first days of hospitalization, according to clinical signs and laboratory abnormalities (Table 2).

Another possibility that should not be overlooked, is the existence of bacteria detected only by qPCR, that belong to a group that has not yet been isolated in cultures, but are potentially pathogenic, especially to preterm infants ${ }^{35}$. Through DNA sequencing coupled to qPCR it would be possible to determine whether these bacteria are the same found in culture-positive cases. These data can be relevant to medical assistance but, in this study, we did not analyse amplification products because we were focused on the study of bacterial load levels and whether they could provide information to increase the understanding of culturenegative neonatal sepsis.

In a previous study, our research group has shown that qPCR is more sensitive than blood cultures and has a high negative predictive value. As a consequence, when this molecular test is negative together with blood culture, qPCR could help to rule out the presence of infection, shortening both, the treatment and the length of hospital stay $^{21}$. Unfortunately, it does not seem that we could use this reasoning to explain the six neonates with negative qPCR and blood cultures, among the 41 culture-negative cases (Table 3). Two neonates had mothers who received antibiotics prior to delivery, reducing the sensitivity of neonatal blood cultures, and all of the six infants had severe clinical and laboratory abnormalities (respiratory distress and perinatal asphyxia, thrombocytopenia, leukopenia or leucocytosis, increased CRP) at least during the first few days after NICU admission. When neonates are critically ill, physicians usually prioritize life support exams, such as blood gases and electrolytes, to the detriment of other exams, so that the volume of blood placed into culture bottles is the remaining amount, which is frequently insufficient and more prone to contamination due to excessive handling. Inadequate blood volumes inserted into culture bottles are the main cause of blood cultures negativity ${ }^{4,9,36}$. In the present study, it is possible to guarantee that at least $1 \mathrm{~mL}$ of blood was used to perform blood cultures so that other causes have to be raised to explain why blood cultures fail to identify neonatal sepsis in cases with bacterial load levels above 1-10 CFU/mL $4,6,7,9,36,37$.

According to the literature, if at least $1 \mathrm{~mL}$ of blood is inserted into culture bottles ${ }^{4,6}$, the automated culture systems used nowadays should be able to detect positive results in the majority of neonates investigated in the present 
study, even in the culture-negative group, as $31 / 35$ culturenegative neonates had bacterial load levels $<50 \mathrm{CFU} / \mathrm{mL}$. The only exceptions would be five infants, two in the culture-positive and three in the culture-negative group, in whom bacterial load levels were 1-10 CFU/mL. (Table 4).

Significantly higher bacterial load levels were observed in the culture-positive group in relation to the culturenegative one (Figure 1), and these differences were found without the exclusion of the two neonates with bacterial load levels $>10^{2} \mathrm{CFU} / \mathrm{mL}$ in the culture-negative group (outliers), otherwise the differences would be even greater.

It is true that the ideal blood volume to ensure reliability of negative blood culture results is still a topic of debate. Schelonka et al. ${ }^{4}$ estimated that a $0.5 \mathrm{~mL}$ inoculum of blood inserted into culture media is inadequate for sensitive and timely detection of bacteremia when the colony count is less than $4 \mathrm{CFU} / \mathrm{mL}$, requiring 1.0-2.0 milliliters of blood to increase bacterial recovery.

Kellogg at al. ${ }^{5}$ claimed that bacteremia is often very low in infants from birth to two months of age and estimated the need of culturing up to $6 \mathrm{~mL}$ of blood, representing around $4.5 \%$ of an infant's total blood volume to achieve an efficient detection of pathogens.

Connell et al. ${ }^{6}$ studied blood volumes submitted for culture in routine clinical practice of pediatric units and established the proportion of blood cultures with a blood volume inadequate for reliable detection of bacteremia. They showed that a negative blood culture result is inevitable for a large proportion of blood cultures due to submission of inadequate blood volume, but they did not state what blood volumes they were referring to as ideal. In that study, even after an educational intervention, nearly $50 \%$ of blood cultures remained inadequate and this percentage was higher in neonatal cases.

In view of the bacterial load levels found in the two groups and because at least $1 \mathrm{~mL}$ of blood was inserted into culture bottles in the present study, we believe that blood volumes of $1 \mathrm{~mL}$ are not always sufficient to detect bacteraemia in neonates, not only in the range of $1-10^{1} \mathrm{CFU} / \mathrm{mL}$, but also in higher concentrations. In the context of this research, it was possible to control the variable represented by the volume of blood, but in clinical practice, this information is not available when medical notes are consulted, however, given its relevance, paediatric units, especially the neonatal ones, should consider the information of blood volumes placed in culture bottles as mandatory.

Other parameters such as the number of blood cultures performed per infection episode, blood collection performed in only one site, inadequate blood collection technique, delayed entry of culture bottles into blood culture machines ${ }^{7-9}$, despite the undeniable difficulties, should also be controlled.
The present study faced limitations such as the impossibility to perform peripheral blood collection from a number of healthy uninfected neonates to perform blood cultures and qPCR, to be able to compare these results with the ones from the culture-positive and negative groups, due to ethical issues. In addition, more collection times, for instance, 48-72 $\mathrm{h}$ after the beginning of antibiotics therapy, one week and two weeks afterwards, at each antibiotic regimen change and immediately before NICUs discharge, analyzing blood cultures and qPCRs in parallel, would be much informative. It would also be interesting to analyze full term and preterm neonates separately, as well as early neonatal sepsis besides late infections. In future studies, subgroups of full-term and preterm neonates, randomized by gestational age, birth weight, onset of symptomatology, and according to the type of isolated bacteria (Gram-positive and Gram-negative) will provide relevant information.

In conclusion, the present study has shown that blood culture-negative neonates do have lower bacteria load levels in their bloodstream when compared to blood culturepositive infants in the context of neonatal sepsis.

\section{CONFLICT OF INTERESTS}

The authors declare that they have no conflicts of interest.

\section{FUNDING}

This work was supported by FAPEMAT (Mato Grosso State Research Foundation, Brazil), process Universal 009/2011, grant $\mathrm{N}^{\circ} 752380 / 2011$, and AUX-PE-DINTER/ NF grant $N^{\circ} 2535 / 2009$ from CAPES - Ministry of Education, Brazil.

\section{AUTHORS' CONTRIBUTIONS}

IS: This study was the subject of her doctoral thesis. She was responsible for collecting all the biological samples, at the three study times. She performed the blood cultures and consulted the hospital records regarding the laboratory tests results. She was responsible for obtaining the grant from FAPEMAT (Mato Grosso State Research Foundation, Brazil). KAK: She performed all qPCR tests and the statistical analyses. JCR: He performed the DNA extractions and helped to build the data bank. LY: She performed the DNA extractions and helped to build the data bank. MIVN: She is a neonatologist who performed the follow-up of all newborns included in the study. PP: She was the official supervisor of the student at the Department 
of Pediatrics, School of Medicine, University of São Paulo, Brazil. She was co-responsible for the grant obtained from FAPEMAT. She helped to write the manuscript. TSO: She was the director of the study, co-responsible for the grant obtained from FAPEMAT; she supervised the development of the qPCR and wrote the manuscript.

\section{ACKNOWLEDGMENTS}

The authors are grateful to the mothers of the studied infants. The authors also thank Paulo Roberto Bezerra de Melo, Associate Professor of the Department of Pediatrics, School of Medicine, Federal University of Mato Grosso, for his assistance, and confident dedication during the development of this study, as well as the nurses of the neonatal intense care unit of Hospital Santa Helena, Cuiaba, and the medical students Natalia de Carvalho Castro and Livia de Sousa Lima Pulcherio for their assistance during data collection.

\section{REFERENCES}

1. United Nations Children's Fund. The state of the world's children 2009: maternal and newborn health. New York: UNICEF; 2008. [cited 2017 Oct 18]. Available from: https://www.unicef.org/ publications/files/SOWC_2009_Main_Report_03112009. pdf

2. World Health Organization. World health statistics: 2010. Geneva: WHO; 2010. [cited 2017 Sept 15]. Available from: http://www. who.int/whosis/whostat/2010/en/

3. Gerdes JS. Diagnosis and management of bacterial infections in the neonate. Pediatr Clin North Am. 2004;51:939-59.

4. Schelonka RL, Chai MK, Yoder BA, Hensley D, Brockett RM, Ascher DP. Volume of blood required to detect common neonatal pathogens. J Pediatr. 1996;129:275-8.

5. Kellogg JA, Ferrentino FL, Goodstein MH, Liss J, Shapiro SL, Bankert DA. Frequency of low level bacteremia in infants from birth to two months of age. Pediatr Infect Dis J. 1997;16:381-5.

6. Connell TG, Rele M, Cowley D, Buttery JP, Curtis N. How reliable is a negative blood culture result? Volume of blood submitted for culture in routine practice in a children's hospital. Pediatrics. 2007;119:891-6.

7. Buttery JP. Blood cultures in newborns and children: optimising an everyday test. Arch Dis Child Fetal Neonatal Ed. 2002;87:F258.

8. Jardine LA, Sturgess BR, Inglis GD, Davies MW. Neonatal blood cultures: effect of delayed entry into the blood culture machine and bacterial concentration on the time to positive growth in a simulated model. J Paediatr Child Health. 2009;45:210-4.

9. Dien Bard J, McElvania TeKippe E. Diagnosis of bloodstream infections in children. J Clin Microbiol. 2016;54:1418-24.
10. Piantino JH, Schreiber MD, Alexander K ,Hageman J. Culture negative sepsis and systemic inflammatory response syndrome in neonates. NeoReviews. 2013;14:e294-303.

11. Cantey JB, Baird SD. Ending the culture of culture-negative sepsis in the neonatal ICU. Pediatrics. 2017;140:e20170044.

12. Chan KY, Lam HS, Cheung HM, Chan AK, Li K, Fok TF, et al. Rapid identification and differentiation of Gram-negative and Gram-positive bacterial bloodstream infections by quantitative polymerase chain reaction in preterm infants. Crit Care Med. 2009;37:2441-7.

13. Pammi M, Flores A, Leeflang M, Versalovic J. Molecular assays in the diagnosis of neonatal sepsis: a systematic review and meta-analysis. Pediatrics. 2011;128:e973-85.

14. Kasper DC, Altiok I, Mechtler TP, Böhm J, Straub J, Langgartner $\mathrm{M}$, et al. Molecular detection of late-onset neonatal sepsis in premature infants using small blood volumes: proof-ofconcept. Neonatology. 2013;103:268-73.

15. Goldstein B, Giroir B, Randolph A. International pediatric sepsis consensus conference: definitions for sepsis and organ dysfunction in pediatrics. Pediatr Crit Care Med. 2005;6:2-8.

16. Manroe BL, Weinberg AG, Rosenfeld CR, Browne R. The neonatal blood count in health and disease. I. Reference values for neutrophilic cells. J Pediatr. 1979;95:89-98.

17. Hofer N, Zacharias E, Müller W, Resch B. An update on the use of C-reactive protein in early-onset neonatal sepsis: current insights and new tasks. Neonatology. 2012;102:25-36.

18. Leuthner SR, Das UG. Low Apgar scores and the definition of birth asphyxia. Pediatr Clin North Am. 2004;51:737-45.

19. Nogueira CA, Momesso CA, Machado RL, Almeida MT, Rossit AR. Desempenho de kits comerciais e protocolos laboratoriais para a extração de DNA genômico bacteriano. Rev Panam Infectol. 2004;6:35-8.

20. Zucol F, Ammann RA, Berger C, Aebi C, Altwegg M, Niggli FK, et al. Real-time quantitative broad-range PCR assay for detection of the 16S rRNA gene followed by sequencing for species identification. J Clin Microbiol. 2006;44:2750-9.

21. Stranieri I, Kanunfre KA, Rodrigues JC, Yamamoto L, Nadaf MI, Palmeira P, et al. Usefulness of a 16S rDNA real-time PCR to monitor neonatal sepsis and to assist in medical decision to discontinue antibiotics. J Matern Fetal Neonatal Med. 2016;29:2141-4.

22. Murray PR, editor. Manual of clinical microbiology. $7^{\text {th }}$ ed. Washington: ASM Press; 1999.

23. Burd EM. Validation of laboratory-developed molecular assays for infectious diseases. Clin Microbiol Rev. 2010;23: 550-76.

24. Jordan JA, Durso MB. Real-time polymerase chain reaction for detecting bacterial DNA directly from blood of neonates being evaluated for sepsis. J Mol Diagn. 2005;7:575-81.

25. Ohlin A, Bäckman A, Björkqvist M, Mölling P, Jurstrand M, Schollin J. Real-time PCR of the 16S-rRNA gene 
in the diagnosis of neonatal bacteraemia. Acta Paediatr. 2008;97:1376-80.

26. Wu YD, Chen LH, Wu XJ, Shang SQ, Lou JT, Du LZ, et al. Gram stain-specific-probe-based real-time PCR for diagnosis and discrimination of bacterial neonatal sepsis. J Clin Microbiol. 2008;46:2613-9.

27. Chen LH, Duan QJ, Cai MT, Wu YD, Shang SQ. Rapid diagnosis of sepsis and bacterial meningitis in children with real-time fluorescent quantitative polymerase chain reaction amplification in the bacterial 16S rRNA gene. Clin Pediatr (Phila). 2009;48:641-7.

28. Ohlin A, Bäckman A, Ewald U, Schollin J, Björkqvist M. Diagnosis of neonatal sepsis by broad-range $16 \mathrm{~S}$ real-time polymerase chain reaction. Neonatology. 2012;101:241-6.

29. Liu CL, Ai HW, Wang WP, Chen L, Hu HB, Ye T, et al. Comparison of 16S rRNA gene PCR and blood culture for diagnosis of neonatal sepsis. Arch Pediatr. 2014;21:162-9.

30. Liu L, Johnson HL, Cousens S, Perin J, Scott S, Lawn JE, et al. Global, regional, and national causes of child mortality: an updated systematic analysis for 2010 with time trends since 2000. Lancet. 2012;379:2151-61.

31. Couto RC, Carvalho EA, Pedrosa TM, Pedroso ER, Neto MC, Biscione FM. A 10-year prospective surveillance of nosocomial infections in neonatal intensive care units. Am J Infect Control. 2007;35:183-9.
32. Carey AJ, Saiman L, Polin RA. Hospital-acquired infections in the NICU: epidemiology for the new millennium. Clin Perinatol. 2008;35:223-49.

33. Ozkan H, Cetinkaya M, Koksal N, Celebi S, Hacımustafaoglu M. Culture-proven neonatal sepsis in preterm infants in a neonatal intensive care unit over a 7 year period: coagulase-negative Staphylococcus as the predominant pathogen. Pediatr Int. 2014;56:60-6

34. Mularoni A, Madrid M, Azpeitia A, Valls i Soler A. The role of coagulase-negative staphylococci in early onset sepsis in a large European cohort of very low birth weight infants. Pediatr Infect Dis J. 2014;33:e121-5.

35. Han YW, Shen T, Chung P, Buhimschi IA, Buhimschi CS. Uncultivated bacteria as etiologic agents of intra-amniotic inflammation leading to preterm birth. J Clin Microbiol. 2009;47:38-47.

36. Iroh Tam PY, Bendel CM. Diagnostics for neonatal sepsis: current approaches and future directions. Pediatr Res. 2017;82:574-83.

37. Gerdes JS. Clinicopathologic approach to the diagnosis of neonatal sepsis. Clin Perinatol. 1991;18:361-81. 